\title{
ARTICLE \\ Knockdown of hypocretin attenuates extended access of cocaine self-administration in rats
}

\author{
Brooke E. Schmeichel ${ }^{1,2}$, Alessandra Matzeu ${ }^{1}$, Pascale Koebel ${ }^{3}{ }^{3}$, Leandro F. Vendruscolo ${ }^{2}$, Harpreet Sidhu ${ }^{1}$, Roxana Shahryari ${ }^{1}$, \\ Brigitte L. Kieffer (iD ${ }^{3,4}$, George F. Koob ${ }^{2}$, Rémi Martin-Fardon (iD) and Candice Contet (iD)
}

The hypocretin/orexin (HCRT) neuropeptide system regulates feeding, arousal state, stress responses, and reward, especially under conditions of enhanced motivational relevance. In particular, HCRT neurotransmission facilitates drug-seeking behavior in circumstances that demand increased effort and/or motivation to take the drug. The present study used a shRNA-encoding adenoassociated viral vector to knockdown Hcrt expression throughout the dorsal hypothalamus in adult rats and determine the role of HCRT in cocaine self-administration. Chronic Hcrt silencing did not impact cocaine self-administration under short-access conditions, but robustly attenuated cocaine intake under extended access conditions, a model that mimics key features of compulsive cocaine taking. In addition, Hcrt silencing decreased motivation for both cocaine and a highly palatable food reward (i.e., sweetened condensed milk; SCM) under a progressive ratio schedule of reinforcement, but did not alter responding for SCM under a fixed ratio schedule. Importantly, Hcrt silencing did not affect food or water consumption, and had no consequence for general measures of arousal and stress reactivity. At the molecular level, chronic Hcrt knockdown reduced the number of neurons expressing dynorphin (DYN), and to a smaller extent melanin-concentrating hormone (MCH), in the dorsal hypothalamus. These original findings support the hypothesis that HCRT neurotransmission promotes operant responding for both drug and non-drug rewards, preferentially under conditions requiring a high degree of motivation. Furthermore, the current study provides compelling evidence for the involvement of the HCRT system in cocaine self-administration also under low-effort conditions in rats allowed extended access, possibly via functional interactions with DYN and MCH signaling.

Neuropsychopharmacology (2018) 43:2373-2382; https://doi.org/10.1038/s41386-018-0054-4

\section{INTRODUCTION}

Independently discovered in 1998 by de Lecea and Sakurai, hypocretin/orexin peptides hypocretin-1 (HCRT-1, also ORX-A) and hypocretin-2 (HCRT-2, also ORX-B), are derived from a common precursor, prepro-HCRT. These HCRT neuropeptides are synthesized in well-defined subregions of the dorsal hypothalamus: lateral hypothalamus proper, dorsomedial hypothalamus, and perifornical area [1-3]. HCRT projections are found throughout the brain and in regions known for their involvement in arousal, stress, and drug and non-drug reinforcement. These areas include, but are not limited to, the central amygdala, nucleus accumbens, ventral tegmental area, arcuate nucleus and paraventricular nucleus of the hypothalamus $[2,4-6]$. HCRT neuropeptides bind two G-protein-coupled receptors, HCRT receptor 1 and receptor 2 (HCRT-R1 and HCRT-R2, respectively; [3]) that also are distributed widely throughout the brain $[7,8]$. Accordingly, the HCRT system is involved in a multitude of physiological functions, such as the regulation of feeding, arousal, sleep/wake states, stress responses, energy homeostasis, and reward (for review, see refs. [9-12]).

An abundant body of literature demonstrates the critical importance of HCRT transmission in the consumption and seeking of various reinforcers, including cocaine [13-24], nicotine [25-28], alcohol [29-35], heroin [36, 37], sucrose, and saccharin [35, 38, 39]. Importantly, HCRT receptor blockade generally does not influence drug self-administration under continuous, low-effort reinforcement, but rather blocks self-administration when the contingency of reinforcement requires higher levels of motivation to acquire the drug [40]. However, recent studies have indicated that acute blockade of HCRT signaling reduces not only the appetitive aspect but also the consummatory aspect of drug taking in dependent animals $[20,33,36]$.

The aim of the present study was to investigate the role of HCRT neurotransmission in cocaine self-administration when rats are given extended access to the drug. The extended access model produces a gradual escalation of cocaine self-administration and an increased motivation to obtain cocaine, along with increases in brain self-stimulation thresholds during withdrawal, stress reactivity, resistance to punishment and reinstatement susceptibility [41-50]. To examine the role of HCRT transmission in this model, Hcrt expression was silenced long-term throughout the dorsal hypothalamus of adult rats using a short hairpin RNA (shRNA)encoding adeno-associated viral (AAV) vector. To further

\footnotetext{
${ }^{1}$ Department of Neuroscience, The Scripps Research Institute, La Jolla, CA 92037, USA; ${ }^{2}$ Neurobiology of Addiction Section, Intramural Research Program, National Institute on

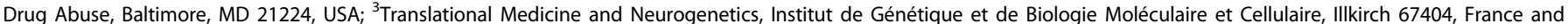
${ }^{4}$ Douglas Institute Research Centre, McGill University, Montréal, QC, Canada Correspondence: Brooke E. Schmeichel (brooke.schmeichel@nih.gov)

These authors contributed equally: Brooke E. Schmeichel and Alessandra Matzeu

These authors jointly supervised this work: Rémi Martin-Fardon and Candice Contet
}

Received: 1 August 2017 Revised: 6 March 2018 Accepted: 7 March 2018

Published online: 6 April 2018 
investigate the function of HCRT in reward consumption and potentially dissociate its role in regulating motivation for drug versus food, the effects of $\mathrm{Hcr}$ silencing on self-administration of a highly palatable food reinforcer (sweetened condensed milk), as well as for regular food pellets and water, were assessed. In addition, given the modulatory role of HCRT in a multitude of behavioral and physiological functions, locomotor activity, anxiety-like behavior, and stress-induced analgesia and corticosterone response were measured to further evaluate the specificity of the behavioral consequences of Hcrt knockdown. Finally, molecular adaptations to prolonged reduction in HCRT signaling were investigated by analyzing the expression of prodynorphin (PDYN) and melanin-concentrating hormone (MCH), two neuropeptides also synthesized in the dorsal hypothalamus.

\section{MATERIAL AND METHODS}

Animals

Forty adult male Wistar rats (Charles River, Raleigh, NC), weighing between $225-275 \mathrm{~g}$ at the beginning of the experiments, were housed in groups of 2-3 per cage in a temperature-controlled (22 ${ }^{\circ} \mathrm{C}$ ) vivarium on a $12 / 12 \mathrm{~h}$ light/dark cycle (lights on at 18:00 h) with ad libitum access to food and water. The rats acclimated to the animal facility for at least 7 days before surgery. All procedures adhered to the National Institutes of Health Guide for the Care and Use of Laboratory Animals and were approved by the Institutional Animal Care and Use Committee of The Scripps Research Institute.

\section{Viral vectors}

Recombinant shRNA-encoding AAV vectors were produced using an AAV helper-free system (Stratagene, France; as described in [51]). In these vectors, the shRNA sequence is expressed under the control of the mU6 promoter, while the enhanced green fluorescent protein (GFP) is expressed under the control of the cytomegalovirus promoter to label transduced cells. The shRNA sequence targeting the Hcrt transcript (shHCRT; $5^{\prime}$ GTCTTCTATCCCTGTCCTAGT-3') was selected using the BLOCK-iT RNAi Designer algorithm (ThermoFisher). A scrambled sequence (shSCR; 5'-GCTTACTITCGGCTCTCTACT-3') was used as negative control. Loop sequence was 5'-AGTCGACA-3' for both. An AAV2 serotype (titer of $7.4 \times 10^{11} \mathrm{GU} / \mathrm{mL}$ ) was used to characterize the time-course of Hcrt knockdown, while AAV5 vectors (titers of $2.4 \times 10^{12}$ for shHCRT and $2.6 \times 10^{12} \mathrm{GU} / \mathrm{mL}$ for shSCR) were used for all behavioral experiments.

\section{AAV injections}

Rats were anesthetized with isoflurane (1-3\%), mounted in a stereotaxic frame (Kopf Instruments, Tujiunga, CA). A stainless steel 30 -gauge double injector was used to inject viral vectors at two mediolateral levels (AP $-2.9 \mathrm{~mm}$ and $\mathrm{ML} \pm 0.5 / 1.75 \mathrm{~mm}$ from bregma, and DV $-8.7 \mathrm{~mm}$ from dura; [52]). Unilateral injections of AAV2-shHCRT were performed for Hcrt knockdown time-course characterization, with brains collected 2 weeks $(n=3), 4$ weeks ( $n$ $=2$ ), or 6 weeks $(n=3)$ after AAV2 injection (see Supplementary Figure S1). Bilateral injections of AAV5-shSCR or AAV5-shHCRT were performed for all behavioral experiments. Injections were made using a micro-infusion pump (Harvard 22 Syringe Pump, Holliston, MA) with a flow rate of $0.5 \mu \mathrm{l} / \mathrm{min}$ over $4 \mathrm{~min}(2 \mu \mathrm{l} / \mathrm{site})$. Injectors remained in place for $10 \mathrm{~min}$ to assure adequate diffusion of the solution and prevent backflow along the injector track.

\section{Experimental design}

Three distinct cohorts were used to test the effect of long-term Hcrt silencing on cocaine self-administration under short- and long-access schedules ( $n=8$ each shSCR and shHCRT, three rats were excluded from each group due to misplaced injections and/ or catheter patency failures), SCM self-administration ( $n=6$ each shSCR and shHCRT, one rat was excluded from each group due to misplaced injections), and general behavior ( $n=6$ each shSCR and shHCRT, one rat was excluded from each group due to misplaced injections. General behavioral testing included food/water selfadministration, locomotor activity, anxiety-like behavior, and stress-induced analgesia and corticosterone response). The timeline of all behavioral testing in each cohort is shown in Supplementary Figure S2. Behavioral testing resumed 2-3 weeks after AAV5 injection and was conducted during the dark phase of the circadian cycle, unless otherwise noted.

\section{Cocaine self-administration}

Rats were surgically prepared with indwelling jugular vein catheters (Dow Corning, Midland, MI) and intravenous selfadministration sessions were conducted as previously described $([53,54]$; Supplementary Methods). Briefly, rats were trained to press one of the two levers on a fixed ratio 1 (FR1) schedule of reinforcement to obtain $0.1 \mathrm{ml}$ of cocaine $(0.50 \mathrm{mg} / \mathrm{kg} /$ infusion) per response in $1 \mathrm{~h}$ sessions. After the acquisition of cocaine selfadministration, rats were injected with AAV vectors and allowed to recover for $\sim 2$ weeks (Figure S1A). Rats were then given short access (ShA; $1 \mathrm{~h}$ ) to cocaine self-administration for 11 sessions and then transitioned to long access $(\operatorname{LgA} ; 6 \mathrm{~h})$ to cocaine for an additional 14 sessions (Figure S2A). Testing under a progressive ratio (PR; see Supplementary Methods) schedule of reinforcement occurred following LgA sessions.

Sweetened condensed milk (SCM) self-administration SCM (Nestlé USA, Inc., Solon, $\mathrm{OH}$ ) self-administration training occurred in daily 30-min sessions on a FR1 TO20 schedule of reinforcement, prior to AAV5 injection. Sessions were initiated by the extension of both levers into the operant chamber, and responses on the active lever resulted in the delivery of SCM $(0.1$ $\mathrm{ml} ; 2: 1 \mathrm{v} / \mathrm{v}$ in water) into a drinking receptacle. Responses on the inactive lever were recorded but had no scheduled consequences. Following AAV injection, the rats were allowed to recover for 3 weeks after which SCM self-administration resumed in 24 daily 30-min sessions (Figure S2B). The rats were then tested on a PR schedule of reinforcement using the same ratio described for cocaine.

Food/water self-administration

Rats underwent three food/water self-administration sessions (22 $\mathrm{h} /$ day, $11 \mathrm{~h}$ dark/11 h light), preceded by two days of habituation. Operant boxes $(22 \times 22 \times 35 \mathrm{~cm})$ were equipped with two holes. Rats were allowed to make nose poke responses in order to obtain food pellets (MLab Rodent Tablet $45 \mathrm{mg}$, TestDiet) from the pellet dispenser (hole on right wall; FR3) or $0.1 \mathrm{ml}$ water from the water dispenser (hole on left wall; FR1). Responses were detected by photobeams mounted in the holes and recorded automatically. Between sessions, animals stayed in their home cage. Food/water self-administration was examined before and after AAV5 injection (Figure S2C).

\section{Locomotor activity}

Locomotor activity was tested in photocell-equipped wire mesh cages holding two photobeams along the lateral walls. Locomotor activity was recorded for three consecutive days ( $22 \mathrm{~h} /$ day). Food and water were available ad libitum. Computer-recorded photobeam breaks were analyzed as a measure of locomotor activity. Crossovers were defined as two consecutive photobeam breaks as the rat moved from front to rear of cage, or vice versa. Detailed descriptions of procedures are provided in the Supplementary Methods. Locomotor activity was monitored before and after AAV5 injection (Figure S2C).

Elevated plus maze

The elevated plus maze apparatus (Kinder Scientific, Poway, CA) comprised four arms (two closed and two open arms). At the 

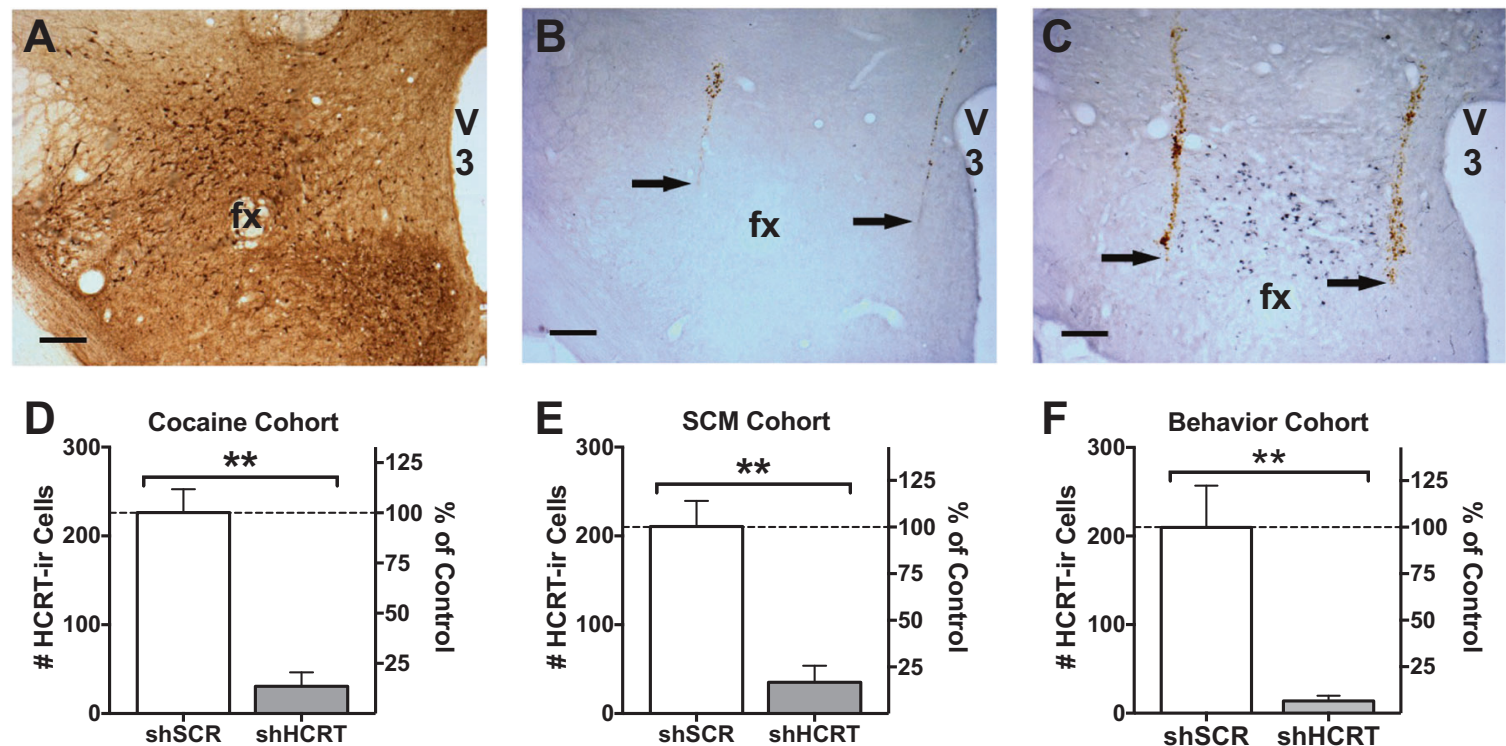

Fig. 1 Histological characterization of viral transduction and quantification of Hcrt knockdown. Rats received double bilateral injections of AAV5-shHCRT $(n=5)$ or AAV5-shSCR $(n=5)$ and were then subjected to behavioral testing. Brains were collected at the end of each experiment for verification of viral transduction by GFP immunohistochemistry (a, brown precipitate). The area of GFP expression consistently encompassed the entire hypothalamus, including areas known to contain HCRT neurons (i.e., lateral hypothalamus proper, perifornical area, and dorsomedial hypothalamus). Adjacent sections were processed for prepro-HCRT immunolabeling (b-c, blue-gray precipitate) to count HCRT neurons in each rat (b, rat injected with AAV5-shHCRT; $\mathbf{c}$, rat injected with AAV5-shSCR). a-c Images were captured at a 5x magnification, scale bar $=250 \mu \mathrm{m}$. Ventral-most end of injector track is indicated with arrows. fx, fornix; V3, third ventricle. d-f shHCRT reduced the number of HCRT neurons by more than $80 \%$ in all three cohorts. Bars represent the mean (+SEM) number of preproHCRT-immunoreactive (HCRT-ir) neurons (left axis) and the percentage of the control group (shSCR; right axis) across three coronal sections. ${ }^{* *} p<0.01$ versus shSCR

beginning of the test, each rat was placed in the center of the maze facing a closed arm and behavior was video recorded for 5 min. Between rats, the apparatus was cleaned with water and dried. Detailed descriptions of procedures are provided in the Supplementary Methods. Time (seconds) spent in each arm was recorded. Elevated plus maze testing was conducted only after AAV5 injection (Figure S2C).

Stress-induced analgesia testing

Stress-induced analgesia testing was conducted as previously described ([55]; detailed descriptions of procedures are provided in the Supplementary Methods). Briefly, each rat was placed individually on a hot plate set to $54^{\circ} \mathrm{C}$. Time (s) to hind-paw lick was recorded, with a cut-off time of $60 \mathrm{~s}$. One hot plate test was conducted before the forced swim test (PRE) and one test $10 \mathrm{~min}$ following forced swim (POST). For forced swim, rats were individually placed in a Plexiglas cylinder filled with water for $5 \mathrm{~min}$. Water was replaced between subjects. Rats underwent stress-induced analgesia testing only after AVV5 injection (Figure S2C).

\section{Plasma corticosterone}

Two hours following elevated plus maze testing (pre-swim condition) and $20 \mathrm{~min}$ after the forced swim test (post-swim condition) blood samples were collected for corticosterone measurements (Figure S2C). In brief, rats were restrained and tail blood $(\sim 0.2 \mathrm{ml})$ was collected into tubes coated with a $10 \%$ ethylenediaminetetraacetic acid solution and centrifuged immediately. Plasma was isolated and stored at $-80^{\circ} \mathrm{C}$. Plasma corticosterone concentrations were determined using a Corticosterone Enzyme Assay Kit (Arbor Assays, Ann Arbor, MI) according to the manufacturer's protocol.

\section{Immunohistochemistry}

Detailed descriptions of immunohistochemical procedures and cell counting are provided in the Supplementary Methods. Briefly, rats were transcardially perfused with paraformaldehyde, brains were post-fixed, and six series of $40 \mu \mathrm{m}$ coronal sections were collected in vials. For each behavioral cohort, two series were processed for immunohistochemistry using antibodies directed against GFP (Abcam; 1:10,000) and preproHCRT (EMD Millipore; 1:1000). In the cohort used for general behavior testing, a third series was used to analyze MCH immunoreactivity (Santa Cruz Biotechnology; 1:1000). GFP immunoreactivity was used to evaluate the location and extent of viral transduction in each rat at the end of the experiment and was consistently identified throughout the HCRT neuronal field (dorsal hypothalamus). HCRT-positive and $\mathrm{MCH}-$ positive cells were counted manually at 20x magnification.

In situ hybridization

Brains were snap-frozen in isopentane and ten series of $20 \mu \mathrm{m}$ coronal cryostat sections were collected on Superfrost Plus slides. Three series were processed for in situ hybridization with probes directed against GFP, preproHCRT (Hcrt), and prodynorphin (Pdyn) mRNAs. Plasmids containing the rat Hcrt and Pdyn cDNAs were kindly donated by Dr. Joel Elmquist at UT Southwestern [3, 56]. Digoxigenin (DIG)-labeled riboprobes were synthesized using a kit (Roche, Indianapolis, IN). Chromogenic in situ hybridization was conducted as described in [57]. The GFP signal was used to define the boundaries of viral transduction in each brain section. Numbers of Hcrt-positive and Pdyn-positive cells in adjacent sections were then counted within the transduced area manually at $\times 20$ magnification.

\section{Statistical analysis}

Statistical analyses were performed using Prism 7 (GraphPad Software, La Jolla, CA). All data are expressed as means and standard errors of the mean (+SEM). Cell counts from the knockdown time-course experiment were normalized to the non-injected control side and analyzed by two-way ANOVA, with brain hemisphere (shHCRT-injected versus contralateral) as withinsubjects factor and time (2, 4 and 6 weeks) as between-subjects factor. Fixed ratio self-administration, locomotor activity, hot plate, 
and corticosterone data were analyzed using a repeated-measures two-way analysis of variance (ANOVA), with viral vector treatment (shHCRT and shSCR) as the between-subjects factor and time as the within-subjects factor. When appropriate, post hoc comparisons were performed using Sidak's multiple-comparison test. Cell counts in behavioral cohorts and elevated plus maze data were analyzed using an unpaired, two-tailed Student's $t$ test. Progressive ratio self-administration data were analyzed using a MannWhitney $U$ Test. $P<0.05$ was considered statistically significant for all tests.

\section{RESULTS}

Characterization of Hcrt knockdown

The AAV5 transduction spread and knockdown efficiency were verified in each rat at the end of each behavioral experiment. GFP immunoreactivity was consistently identified throughout the HCRT neuronal field (Fig. 1a). Bilateral injections of AAV5-shHCRT robustly silenced HCRT expression (Fig. 1b, c). The number of HCRT cells was reduced by more than $80 \%$ compared to shSCR rats in each behavioral cohort (Fig. $1 \mathrm{~d}, t_{(8)}=6.42, p<0.001$; Fig. 1e, $t_{(8)}=5.10, p<0.001$; Fig. 1f, $\left.t_{(8)}=4.13, p<0.01\right)$.

Hcrt knockdown reduces low-effort cocaine self-administration selectively in dependent rats

There was no significant difference between shHCRT and shSCR ( $n$ $=5$, each) rats in ShA cocaine self-administration under an FR1 schedule (Fig. 2a; Group: $F_{(1,9)}=2.43, p=0.15$.; Session: $F_{(10,90)}$ $=0.70, p=0.72$; Group xsession: $\left.F_{(10,90)}=0.47, p=0.91\right)$. However, upon LgA to cocaine self-administration, shHCRT significantly attenuated cocaine self-administration under both an FR1 schedule (Fig. 2b; Group: $F_{(1,8)}=6.24, p<0.05$; Session: $F_{(13,104)}=1.07, p=0.39$; Group $\times$ session: $\left.F_{(13,104)}=1.09, p=0.38\right)$ and a PR schedule of reinforcement (Fig. $2 c ; U_{(8)}=0, Z=2.51, p<$ $0.05)$. These results indicate that HCRT transmission contributes to cocaine self-administration under low-effort conditions in extended access rats, but not in limited access rats.

Hcrt knockdown reduces SCM self-administration under PR reinforcement

There was no significant difference between shHCRT and shSCR ( $n$ $=5$, each) rats in SCM self-administration under an FR1 schedule (Fig. 3a; Group: $F_{(1,8)}=1.07, p=0.33$; Session: $F_{(11,88)}=1.71, p=$ 0.08; Groupxsession: $\left.F_{(11,88)}=0.50, p=0.90\right)$. In contrast, Hcrt knockdown significantly attenuated responding for SCM under a PR schedule of reinforcement (Fig. $3 \mathrm{~b} ; U_{(8)}=2.50, Z=1.98, p<$ $0.05)$. These results indicate that the influence of HCRT on the selfadministration of palatable food by sated rats is restricted to higheffort conditions.

Hcrt knockdown has no effect on general behavior

There was no significant difference between shHCRT and shSCR ( $n$ $=5$, each) rats in body weight or food pellet self-administration under an FR3 schedule (Fig. 4a,b; Body weight: Group: $F_{(1,8)}=0.63$, $p=0.45$; Time: $F_{(5,40)}=159.1, p<0.001$; Group $\times$ time: $F_{(5,40)}=0.46$, $p=0.79$; Food: Group: $F_{(1,8)}=3.48, p=0.10$; Time: $F_{(1,8)}=130.50$, $p<0.001$; Group xtime: $\left.F_{(1,8)}=0.003, p=0.96\right)$. Similarly, there was no significant difference between shHCRT- and shSCR-treated rats in water self-administration under an FR1 schedule (Fig. 4c; Group: $F_{(1,8)}=1.16, p=0.31$; Time: $F_{(1,8)}=118.20, p<0.001$; Group $x$ time: $\left.F_{(1,8)}=1.30, p=0.29\right)$. There was also no significant effect of shHCRT injection on the number of crossovers in the activity box compared to shSCR-treated control rats (Fig. 4d; Group: $F_{(1,8)}=$ 2.20, $p=0.18$; Condition: $F_{(3,24)}=30.53, p<0.001$; Groupxcondition: $\left.F_{(3,24)}=0.002, p=0.96\right)$ or on the percentage of time spent in the open arms of the elevated plus maze (Fig. $4 \mathrm{e} ; t_{(8)}=0.46, p=$ 0.66). Additionally, shHCRT rats showed no significant difference in latency to thermal nociception on the hot plate test prior to forced
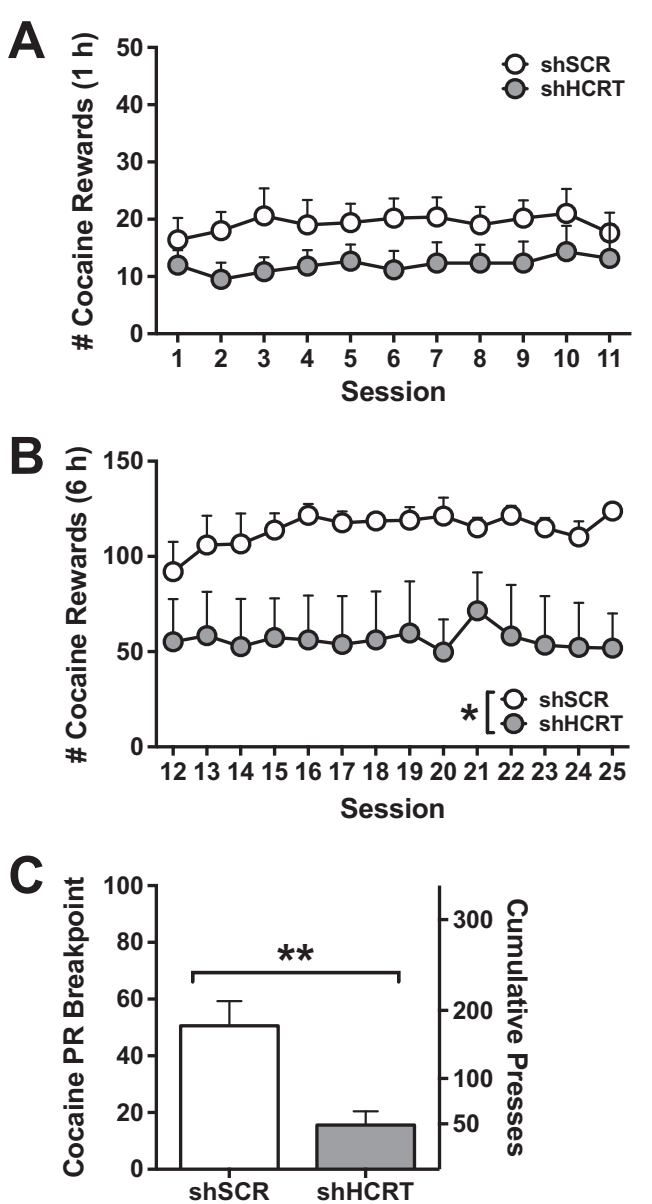

Fig. 2 Long-term Hcrt knockdown reduces cocaine selfadministration in dependent rats. a, b Symbols represent mean number of cocaine rewards ( + SEM) per session. AAV5-shHCRT $(n=$ 5) had no effect on cocaine intake over 11 sessions of short access self-administration (a; $1 \mathrm{~h}$; Session 1-11), whereas it significantly reduced cocaine intake over 14 sessions of long access selfadministration (b; $6 \mathrm{~h}$; Session 12-25) compared to AAV5-shSCR ( $n$ $=5)$. ${ }^{*} p<0.05$ versus shSCR. c Bars represent mean PR breakpoints (+SEM; left axis) and cumulative presses (+SEM; right axis). shHCRT rats showed significantly reduced cocaine intake on a PR schedule of reinforcement compared to shSCR rats. ${ }^{* *} p<0.01$ versus shSCR

swim stress compared to shSCR rats, and stress produced an equivalent analgesic effect in shHCRT and shSCR rats (Fig. 4f; Group: $F_{(1,8)}=0.31, p=0.59$; Condition: $F_{(1,8)}=86.45, p<0.001$; Groupxcondition: $\left.F_{(1,8)}=1.21, p=0.30\right)$. Finally, there was no significant effect of $\mathrm{Hcrt}$ knockdown on basal and stressstimulated corticosterone release (Fig. 4g; Group: $F_{(1,8)}=0.45, p$ $=0.52$; Condition: $F_{(1,8)}=11.97, p<0.01$; Groupxcondition: $F_{(1,8)}=$ $0.92, p=0.37)$. Altogether, these data indicate that there is no effect of shHCRT on food/water intake, locomotion, or on measures of anxiety or stress responses in the absence of cocaine. These results demonstrate that the effects of Hcrt knockdown on cocaine and SCM self-administration cannot be attributed to a non-specific disruption of behavioral performance or basal stress sensitivity.

Adaptations in local neuropeptide expression Molecular adaptations to chronic Hcrt knockdown were investigated by examining two other neuropeptides showing prominent expression in the dorsal hypothalamus, PDYN and MCH (Fig. 5). Cellular co-localization of PDYN and HCRT in the rodent lateral hypothalamus is virtually complete, with nearly all neurons 

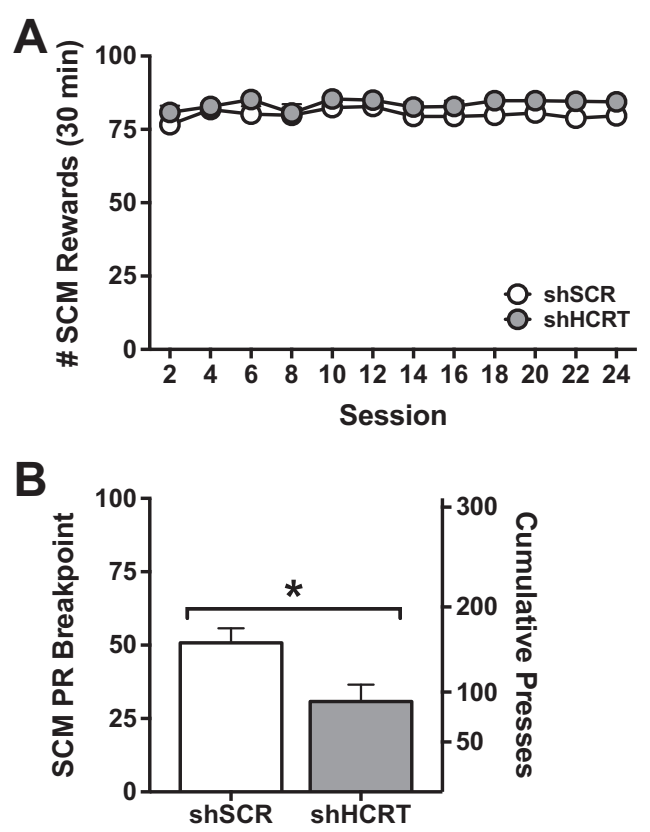

Fig. 3 Long-term Hcrt knockdown reduces sweetened condensed milk self-administration only under a progressive ratio schedule of reinforcement. a Symbols represent mean number of sweetened condensed milk (SCM) rewards (+SEM) per session. AAV5-shHCRT ( $n$ $=5)$ had no effect on SCM intake over 24 sessions of selfadministration ( $30 \mathrm{~min}$ ) compared to AAV5-shSCR $(n=5)$. b Bars represent mean PR breakpoints ( + SEM; left axis) and cumulative presses (+SEM; right axis). shHCRT rats did show significantly reduced SCM intake on a PR schedule of reinforcement compared to shSCR rats. ${ }^{*} p<0.05$ versus shSCR

expressing HCRT mRNA or peptide also expressing PDYN mRNA or peptide, and vice versa $[18,58]$. In contrast, $\mathrm{MCH}$ neurons are intermingled with HCRT neurons with no overlap between the two populations [59, 60]. Pdyn mRNA expression in the dorsal (i.e., dorsomedial hypothalamus and lateral hypothalamic area) and ventral (i.e., ventromedial hypothalamus and arcuate nucleus) parts of the hypothalamus was examined in brain sections adjacent to those analyzed for the time-course of Hcrt knockdown (Fig. 5a). Long-term Hcrt knockdown significantly reduced Pdyn expression in the dorsal part of the hypothalamus where Pdyn is expressed by HCRT neurons (Fig. 5b; Group: $F_{(1,5)}=9.91, p<0.05$; Time: $F_{(2,5)}=0.22, p=0.12$; Group $\mathrm{x}$ time: $\left.F_{(2,5)}=0.15, p=0.86\right)$, but not in the ventral part of the hypothalamus where there are no HCRT neurons (Fig. 5c; Group: $F_{(1,5)}=0.56, p=0.41$.; Time: $F_{(2,5)}$ $=0.03, p=0.97$; Group $\times$ time: $\left.F_{(2,5)}=0.05, p=0.95\right)$. MCH immunoreactivity was examined in brain sections from the third, general behavior cohort (Fig. $5 \mathrm{~d}$, e). There was a non-significant trend for a reduction in the number of $\mathrm{MCH}$-positive neurons within the dorsal hypothalamus following long-term Hcrt knockdown (Fig. 5e, $t_{(8)}=1.98, p=0.08$ ).

To further evaluate whether the reduction in Pdyn mRNA and $\mathrm{MCH}$ protein expression resulted from compensatory adaptations to prolonged Hcrt knockdown rather than a direct off-target effect of shHCRT, we examined the influence of shHCRT on HCRT, PDYN and PMCH expression in transfected HEK293 cells (Supplementary Methods and Figure S4). shHCRT reduced HCRT production ( $p<$ 0.01 compared to shSCR) but did not alter PDYN and PMCH levels (Figure S4B).

\section{DISCUSSION}

The HCRT system has been implicated in the motivation to consume and seek drugs of abuse, but its role in extended access drug taking associated with compulsive-like cocaine use is poorly understood. Here, a genetic approach was used to probe the role of HCRT neurotransmission in extended access cocaine selfadministration. Efficient, long-lasting knockdown of Hcrt expression throughout the rat dorsal hypothalamus was achieved by virally mediated RNA interference, circumventing the need to chronically administer HCRT receptor antagonists. Our results confirm previous pharmacological evidence that HCRT neurotransmission promotes operant responding for both drug and non-drug rewards under motivationally salient, high-effort conditions $[40,61]$. Furthermore, the present study demonstrates that HCRT neurotransmission contributes to cocaine intake even under a low-effort contingency when access to cocaine selfadministration is extended. Altogether, these data provide novel insights into the role of HCRT in drug use under conditions of pathologic motivation, and validates virally mediated $\mathrm{Hcrt}$ silencing as a valuable approach to investigate the behavioral relevance of HCRT neurotransmission in rodent models.

A role for HCRT in the transition to cocaine addiction-like behavior Our finding that Hcrt knockdown did not affect cocaine selfadministration under low-effort conditions (FR1 schedule of reinforcement) in rats offered $1 \mathrm{~h}$ daily access to the drug corroborates previous pharmacological studies. HCRT-R1 antagonists show no or minimal effects on low-effort, FR1 responding for cocaine self-administration in animals allowed limited access to cocaine $[14,20,21]$. Likewise, intracerebral injection of HCRT-1 does not affect FR1 responding for cocaine [13, 62]. Furthermore, the lack of effect on FR1 responding under short-access conditions we observed here is unlikely to result from inefficient $\mathrm{Hcrt}$ silencing at the time of testing (i.e., 2-3 weeks post-injection) as we confirmed a nearly $85 \%$ knockdown of Hcrt as early as two weeks following AAV injection (Figure S1). Altogether, the genetic approach used in the present study lends further support to the hypothesis that HCRT transmission is not necessary for the primary rewarding effects of the drug under conditions of low incentive motivation.

In contrast, Hcrt silencing strongly reduced FR1 cocaine responding in extended access rats. This finding suggests that HCRT neurotransmission may contribute to the activation of stress systems and dampening of reward systems, which are associated with extended access to cocaine self-administration and are hypothesized to drive excessive, compulsive-like cocaine taking in addiction (for review, [63]). In support of this hypothesis, central infusion of HCRT-1 peptide reduces brain reward sensitivity [13, 64], suggesting an inhibitory action on reward systems. Furthermore, central HCRT-1 administration reinstates previously extinguished drug-seeking, whereas HCRT-R1 antagonism readily blocks stress-induced reinstatement of cocaine-seeking [13, 20, $23,24,65-67]$. Both preclinical and clinical work has established a role for HCRT in stress responses to anxiety- and panic-associated behaviors $[11,65,68,69]$. However, whether HCRT-mediated stress reactivity is sensitized under conditions of chronic cocaine exposure, promoting the hyper-aroused state required for drug taking, has yet to be determined. Additionally, it will be of interest to examine the effect of Hcrt knockdown on stress-induced reinstatement cocaine-seeking in future studies.

The present results extend our understanding of HCRT signaling participation in cocaine reinforcement, such that HCRT contributes not only to high-effort but also to low-effort responding under extended access conditions. Furthermore, our findings suggest the feasibility of normalizing compulsive cocaine intake in addicted individuals via sustained inhibition of HCRT signaling.

HCRT in reward-based feeding

Hcrt knockdown also decreased the motivation to obtain palatable food (SCM) under a PR schedule of reinforcement, which suggests a role for HCRT in food-seeking under high-effort conditions, as 

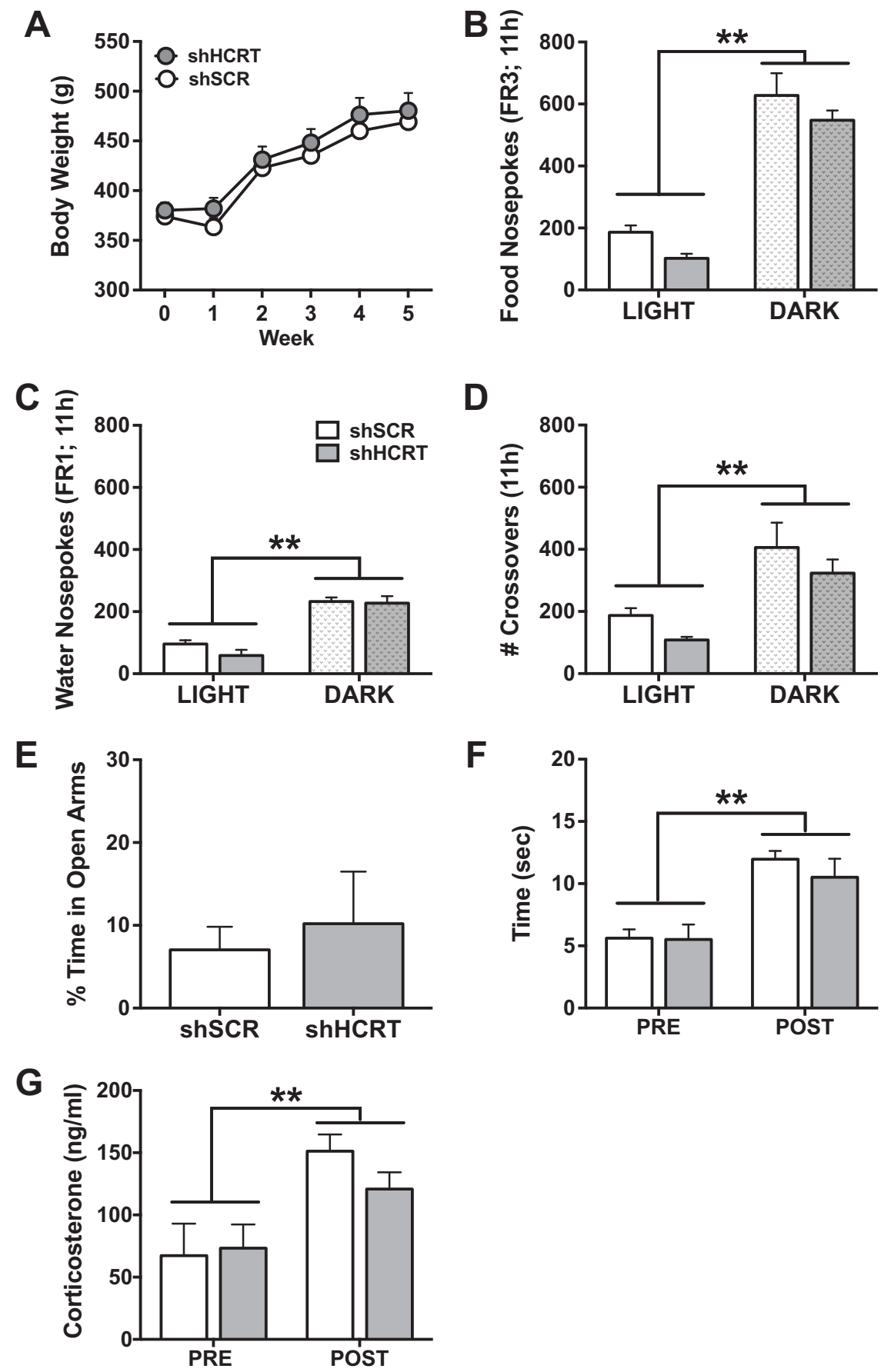

Fig. 4 Long-term Hcrt knockdown has no effect on general measures of behavior and physiology. a Symbols represent mean body weight (g) each week following AAV5-shHCRT or AAV5-shSCR injection (Week 0). There was no significant difference in body weight between shHCRT and shSCR rats $(n=5$, each). b-c Bars represent the mean number of food pellet (b) or water (c) rewards $(+$ SEM) per $11 \mathrm{~h}$ time epoch. There was no significant difference between shHCRT and shSCR rats in number of food pellets (FR3) or water (FR1) rewards in either the light or dark phase of the circadian cycle. ${ }^{* *} p<0.01$ versus LIGHT. d Bars represent the mean number of crossovers (+SEM) in a locomotor activity box per $11 \mathrm{~h}$ time epoch. There was no significant difference between shHCRT and shSCR rats in number of crossovers in either the light or dark phase. ${ }^{* *} p<0.01$ versus LIGHT. (e) Bars represent percentage of time spent in the open arms (+SEM) of an elevated plus maze. There was no significant difference in anxiety-like behavior between shHCRT and shSCR rats. $f$ Bars represent time (sec; + SEM) to hind paw lick on a $54{ }^{\circ} \mathrm{C}$ hot plate prior to (PRE) or following (POST) forced swim stressor. There was a significant main effect of stress resulting in an increase of withdrawal latency time following forced swim (stress-induced analgesia), but no significant difference between shHCRT and shSCR rats. ** $p<0.01$ versus PRE. g Bars represent mean plasma corticosterone levels ( $\mathrm{ng} / \mathrm{ml} ;+\mathrm{SEM}$ ) prior to (PRE) or following (POST) forced swim stressor. There was a significant effect of stress on corticosterone release, but no significant difference between shHCRT and shSCR rats. ${ }^{* *} p<0.01$ versus PRE 

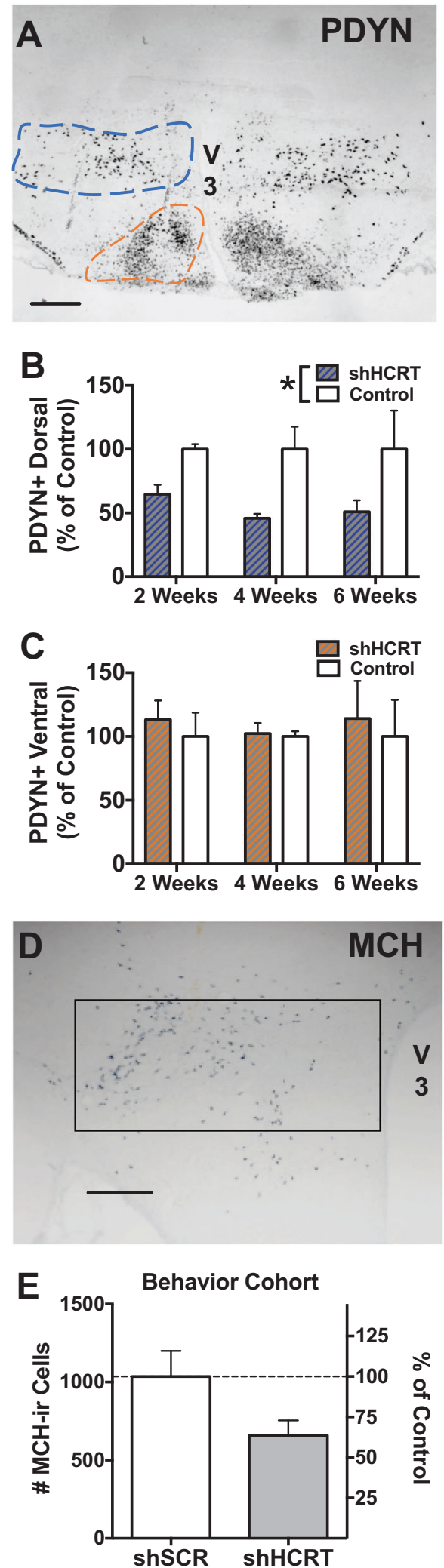

well as during the consumption of highly palatable foods. This finding is consistent with the existing literature (for review, [40]). HCRT was initially reported to regulate general feeding behavior by demonstrating that central administration of HCRT-1 and HCRT2 stimulates feeding [3], whereas blockade of HCRT signaling with an HCRT-R1 antagonist, an anti-HCRT antibody, or genetic
Fig. 5 Long-term $\mathrm{Hcrt}$ knockdown produces adaptations in local neuropeptide expression. a-c For quantification of $P d y n+$ cells, rats received unilateral double injections of AAV2-shHCRT, with the contralateral hemisphere used as a control site, and brains were collected 2, 4, or 6 weeks later ( $n=2-3$ per time-point). a Pdyn expression was examined using in situ hybridization. V3, third ventricle; scale bar $=500 \mu \mathrm{m}$. The number of Pdyn + cells was then quantified within the HCRT neuronal field (i.e., dorsal hypothalamus; blue outline) and more ventrally on the same sections (orange outline). b, c Bars represent mean cell counts expressed as a percentage of the control hemisphere (\% of Control; +SEM) across three coronal sections. b Hcrt knockdown was accompanied by a concomitant reduction in the number of $P d y n+$ neurons in the dorsal hypothalamus (blue outline). ${ }^{*} p<0.05$ versus contralateral control hemisphere. c The viral vector had no effect on Pdyn+ neurons located more ventrally (orange outline). d, e For quantification of MCH cells following Hcrt knockdown, brain sections from the general behavior cohort were processed for $\mathrm{MCH}$-positive immunolabeling. d Representative photomicrograph of $\mathrm{MCH}-$ immunostaining. V3, third ventricle; scale bar $=500 \mu \mathrm{m} . \mathrm{MCH}-$ immunoreactive ( $\mathrm{MCH}$-ir) cells were counted bilaterally within the dorsal hypothalamus (boxed area) in AAV5-shSCR and AAV5shHCRT-treated animals ( $n=5$, each). e Hcrt knockdown was accompanied by a non-significant reduction in the number of MCH-ir cells $(p=0.08$, shSCR vs shHCRT). Bars represent the mean (+SEM) number of MCH-ir neurons (left axis) or the percentage of the control group (shSCR; right axis) across three coronal sections

inactivation of Hcrt reduces food intake [70-72]. Subsequent studies revealed that the modulation of feeding by HCRT is restricted to the light phase of the circadian cycle $[73,74]$. Our observations are consistent with the latter findings, as Hcrt silencing did not significantly affect responding for regular food pellets overall, but there was a trend for reduced food selfadministration during the light phase. HCRT is also likely to play an important part in the hedonic aspect of feeding (i.e., feeding beyond caloric needs; [75]). Consistent with this hypothesis, central administration of HCRT-1 increases the motivation for palatable food, whereas blockade of HCRT signaling with an HCRTR1 antagonist attenuates this reward-based feeding [61, 76, 77]. Therefore, together with these studies, our data support the hypothesis that HCRT signaling mediates motivation to obtain palatable food.

HCRT modulation of arousal-dependent behavior

The present study showed that Hcrt knockdown did not affect food or water self-administration, locomotor activity, or sensitivity to tests of anxiety-like behavior and stress-induced analgesia or corticosterone release. At first glance, these results may be surprising considering the established role of HCRT in a multitude of arousal-dependent behaviors and physiological functions including energy homeostasis, sleep/wake state, response to stress, and reinforcer-motivated behavior (for review, see refs. [912]). It is possible that the lack of significant behavioral alterations following virally mediated $\mathrm{Hcr}$ silencing resulted from compensatory activity of the few remaining HCRT-positive neurons, which may have been sufficient to modulate relevant arousal-dependent behaviors. In addition, the fact that Hcrt expression was silenced in adult animals may explain the discrepancy with results obtained upon constitutive deletion of Hcrt in knockout mice, whose phenotype may partially result from developmental compensations (for review, see ref. [78]).

In the present study, shHCRT-treated rats maintained normal body weights, levels of food and water consumption, and locomotor activity. In particular, there was no detectable effect of Hcrt silencing on these measures during the dark phase of the circadian cycle, when cocaine and SCM self-administration sessions were conducted. This rules out performance disruption as a potential explanation for the reduction in operant responding for cocaine and SCM. 
In addition, Hcrt knockdown did not produce a significant blunting of stress sensitivity in the absence of cocaine, as measured by anxiety-like behavior in the elevated plus maze and thermal analgesia or plasma corticosterone elevation following forced swim stress. This suggests that HCRT neurotransmission does not indiscriminately contribute to all responses to psychological or physiological stressors and that the implication of HCRT signaling in extended access cocaine self-administration is specific to homeostasis and affective state dysregulation associated with withdrawal from chronic, excessive cocaine intake.

Molecular neuroadaptations following virally mediated Hcrt knockdown in the rat

To date, physiological functions of the HCRT neuropeptide system have mainly been investigated using acute pharmacological manipulation or constitutive gene deletion. A limited number of studies have used alternative approaches such as local infusions of small interfering RNAs or antisense morpholinos for the transient knockdown of HCRT [79-82], or local injection of shRNA-encoding viral vectors for the long-term knockdown of HCRT, HCRT-R1 or HCRT-R2 [83-87]. Here we report virally mediated knockdown of HCRT in adult rats. Thus, the novelty of our approach warranted further examination of molecular adaptations potentially elicited by sustained silencing of Hcrt expression in the adult brain.

In the dorsal hypothalamus, DYN and HCRT are expressed by the same neurons and packaged in the same vesicles $[18,58]$. Furthermore, these neurons synapse onto each other and local release of DYN tonically inhibits neighboring HCRT neurons [88]. We found that Hcrt knockdown was accompanied by a $\sim 34-53 \%$ reduction in the number of Pdyn-positive cells in the HCRT neuronal field (i.e., dorsal hypothalamus). Importantly, the shHCRT vector had no effect on Pdyn expression in more ventral regions of the hypothalamus, thereby ruling out an off-target effect of the shRNA sequence on Pdyn mRNA, or a neurotoxic effect of viral transduction or GFP expression. This observation suggests that $P d y n$ downregulation is a compensatory adaptation that occurs downstream of $\mathrm{Hcrt}$ knockdown. Follow-up experiments in transfected cells confirmed that shHCRT does not directly reduce PDYN levels, further corroborating this interpretation.

DYN has been shown to balance the effects of HCRT on neuronal excitability in a subset of ventral tegmental area dopaminergic neurons $[18,89]$. Thus, in shHCRT-treated rats, the reduced need to control the activity of dopaminergic neurons in the absence of excitatory HCRT transmission could have triggered Pdyn downregulation. At the behavioral level, intraventricular administration of HCRT-1 or systemic activation of kappa opioid receptors (KOR) both elevate intracranial self-stimulation thresholds $[13,90]$, but concomitant blockade of HCRT-R1 and KOR revealed that HCRT and DYN actually exert opposing influences on cocaine self-administration, brain reward, impulsivity and cocaineseeking behavior $[18,91]$. It is therefore possible that the downregulation of Pdyn associated with Hort knockdown may have potentiated, or conversely attenuated, the amplitude of phenotypic changes observed in shHCRT rats. The potential role of HCRT-DYN interaction in extended access cocaine selfadministration is an important topic for future studies.

Additionally, we observed that Hcrt knockdown induced a moderate, although not statistically significant, decrease in the number of $\mathrm{MCH}$-positive cells ( $36 \%$ reduction; $p=0.08)$. $\mathrm{MCH}$ neurons are intermingled with HCRT neurons $[59,60]$ and several studies have indicated a direct connectivity between these two cell types, whereby HCRT excites $\mathrm{MCH}$ neurons and $\mathrm{MCH}$ counters the activation of HCRT neurons [92-96]. The inhibitory tone exerted by $\mathrm{MCH}$ on HCRT neurons could explain how $\mathrm{MCH}$ downregulation may represent a network adaptation to sustained inhibition of HCRT transmission. A recent study also revealed that HCRT neurons inhibit $\mathrm{MCH}$ neurons via a local microcircuit involving HCRT-induced GABA release [97]. It is therefore possible that $\mathrm{MCH}$ was downregulated to compensate for the loss of HCRTdriven inhibition of $\mathrm{MCH}$ neurons in shHCRT rats. As for DYN, heterologous expression analysis indicated that shHCRT does not directly reduce the expression of $\mathrm{PMCH}$, which suggests that $\mathrm{MCH}$ downregulation in rats injected with the AAV5-shHCRT vector indeed resulted from compensatory adaptations. At the behavioral level, blocking $\mathrm{MCH}$ signaling attenuates cocaine selfadministration, as well as cue- and drug-induced reinstatement [98]. Similar effects were reported for alcohol [99]. Thus, $\mathrm{MCH}$ downregulation may have contributed to decreasing cocaine intake in shHCRT rats, but this would need to be directly tested in future studies.

Finally, the adaptations elicited by sustained inhibition of HCRT signaling in adulthood may differ from developmental compensations elicited by constitutive gene knockout or genetic ablation of neurons (e.g., [87]). Notably, Pdyn expression in the dorsal hypothalamus is unchanged in Hcrt knockout mice and $\mathrm{MCH}$ neurons are not affected in mice that have lost HCRT neurons shortly after birth [58, 70]. Although counterintuitive, these observations combined with our findings suggest that late-onset downregulation of HCRT signaling is more prone to elicit perturbations in crosstalking neuropeptide systems than the life-long absence of HCRT. An important implication of this interpretation is that chronic administration of a HCRT receptor antagonist in adult subjects would be expected to produce similar reductions in hypothalamic PDYN and $\mathrm{MCH}$ expression, which may in turn enhance the therapeutic efficacy of this approach in the treatment of cocaine use disorder.

\section{CONCLUSION}

In summary, long-term Hcrt silencing via virally mediated RNA interference yielded novel insights into the role of HCRT transmission in cocaine and palatable food reinforcement without affecting general activity, operant performance, or stress reactivity. Hcrt knockdown attenuated cocaine and SCM self-administration selectively under high-effort conditions and reduced cocaine intake under conditions of high motivation associated with extended access. These findings suggest a specific functional role for HCRT signaling in compulsive-like cocaine self-administration, as well as in reward-based feeding behavior.

\section{ACKNOWLEDGEMENTS}

This research was supported by grants from the National Institute on Drug Abuse, DA004398 (GFK), DA033344 (RMF), DA036355 (BES), the National Institute of Alcohol Abuse and Alcoholism, AA016658 (BLK), AA024198/AA006420/AA021491 (CC) and AA024146/AA006420/AA022249 (RMF), and by the Pearson Center for Alcoholism and Addiction Research. A portion of this work was also supported by the Intramural Research Program of the National Institute on Drug Abuse. We thank Zhi-Bing You for assistance with corticosterone measurements. This is article number 29409 from the Scripps Research Institute.

\section{ADDITIONAL INFORMATION}

The online version of this article (https://doi.org/10.1038/s41386-018-0054-4) contains supplementary material, which is available to authorized users.

Competing interests: The authors declare no competing interests.

Publisher's note: Springer Nature remains neutral with regard to jurisdictional claims in published maps and institutional affiliations.

\section{REFERENCES}

1. de Lecea L, Kilduff TS, Peyron C, Gao X, Foye PE, Danielson PE, et al. The hypocretins: hypothalamus-specific peptides with neuroexcitatory activity. Proc Natl Acad Sci USA. 1998;95:322-7.

2. Peyron C, Tighe DK, van Den Pol AN, de Lecea L, Heller HC, Sutcliffe JG, et al. Neurons containing hypocretin (orexin) project to multiple neuronal systems. J Neurosci. 1998;18:9996-10015. 
3. Sakurai T, Amemiya A, Ishii M, Matsuzaki I, Chemelli RM, Tanaka H, et al. Orexins and orexin receptors: a family of hypothalamic neuropeptides and $G$ proteincoupled receptors that regulate feeding behavior [comment]. Cell. 1998;92:1.

4. Nambu T, Sakurai T, Mizukami K, Hosoya Y, Yanagisawa M, Goto K. Distribution of orexin neurons in the adult rat brain. Brain Res. 1999;827:243-60.

5. Baldo BA, Daniel RA, Berridge CW, Kelley AE. Overlapping distributions of orexin/ hypocretin- and dopamine-beta-hydroxylase immunoreactive fibers in rat brain regions mediating arousal, motivation, and stress. J Comp Neurol. 2003;464:220-37.

6. Schmitt $\mathrm{O}$, Usunoff $\mathrm{KG}$, Lazarov NE, Itzev DE, Eipert $\mathrm{P}$, Rolfs $\mathrm{A}$, et al. Orexinergic innervation of the extended amygdala and basal ganglia in the rat. Brain Struct Funct. 2012;217:233-56

7. Marcus JN, Aschkenasi CJ, Lee CE, Chemelli RM, Saper CB, Yanagisawa M, et al. Differential expression of orexin receptors 1 and 2 in the rat brain. J Comp Neurol. 2001;435:6-25.

8. Trivedi P, Yu H, MacNeil DJ, Van der Ploeg LH, Guan XM. Distribution of orexin receptor mRNA in the rat brain. FEBS Lett. 1998;438:71-75.

9. Berridge CW, España RA. Hypocretin/orexin in stress and arousal. In: $L$ de Lecea, JG Sutcliffe (Eds.). Hypocretins: integrators of physiological functions. Springer, Singapore (2005), pp. 351-368.

10. Boutrel B, de LL. Addiction and arousal: the hypocretin connection. Physiol Behav. 2008:93:947-51.

11. Johnson PL, Truitt W, Fitz SD, Minick PE, Dietrich A, Sanghani S, et al. A key role for orexin in panic anxiety. Nat Med. 2010;16:111-5.

12. Tsujino N, Sakurai T. Orexin/hypocretin: a neuropeptide at the interface of sleep, energy homeostasis, and reward system. Pharmacol Rev. 2009;61:162-76.

13. Boutrel B, Kenny PJ, Specio SE, Martin-Fardon R, Markou A, Koob GF, et al. Role for hypocretin in mediating stress-induced reinstatement of cocaine-seeking behavior. Proc Natl Acad Sci USA. 2005;102:19168-73.

14. España RA, Oleson EB, Locke JL, Brookshire BR, Roberts DCS, Jones SR. The hypocretin-orexin system regulates cocaine self-administration via actions on the mesolimbic dopamine system. Eur J Neurosci. 2010;31:336-48.

15. Hollander JA, Pham D, Fowler CD, Kenny PJ. Hypocretin-1 receptors regulate the reinforcing and reward-enhancing effects of cocaine: pharmacological and behavioral genetics evidence. Front Behav Neurosci. 2012;6:47.

16. Martin-Fardon R, Cauvi G, Kerr TM, Weiss F (2016). Differential role of hypothalamic orexin/hypocretin neurons in reward seeking motivated by cocaine versus palatable food. Addict Biol. https://doi.org/10.1111/adb.12441.

17. Martin-Fardon R, Weiss F. Blockade of hypocretin receptor-1 preferentially prevents cocaine seeking: comparison with natural reward seeking. Neuroreport. 2014a;25:485-8.

18. Muschamp JW, Hollander JA, Thompson JL, Voren G, Hassinger LC, Onvani S, et al. Hypocretin (orexin) facilitates reward by attenuating the antireward effects of its cotransmitter dynorphin in ventral tegmental area. Proc Natl Acad Sci USA. 2014;111:E1648-55.

19. Prince $C D$, Rau AR, Yorgason JT, España RA. Hypocretin/Orexin regulation of dopamine signaling and cocaine self-administration is mediated predominantly by hypocretin receptor 1. ACS Chem Neurosci. 2015;6:138-46.

20. Schmeichel BE, Herman MA, Roberto M, Koob GF. Hypocretin neurotransmission within the central amygdala mediates escalated cocaine self-administration and stress-induced reinstatement in rats. Biol Psychiatry. 2017;81:606-15.

21. Smith RJ, See RE, Aston-Jones G. Orexin/hypocretin signaling at the orexin 1 receptor regulates cue-elicited cocaine-seeking. Eur J Neurosci. 2009:30:493-503.

22. Smith RJ, Tahsili-Fahadan P, Aston-Jones G. Orexin/hypocretin is necessary for context-driven cocaine-seeking. Neuropharmacology. 2010;58:179-84.

23. Wang B, You Z-B, Wise RA. Reinstatement of cocaine-seeking by hypocretin (orexin) in the ventral tegmental area: Independence from the local CRF network. Biol Psychiatry. 2009;65:857-62.

24. Zhou L, Ghee SM, Chan C, Lin L, Cameron MD, Kenny PJ, et al. Orexin-1 receptor mediation of cocaine seeking in male and female rats. J Pharmacol Exp Ther. 2012;340:801-9.

25. Hollander JA, Lu Q, Cameron MD, Kamenecka TM, Kenny PJ. Insular hypocretin transmission regulates nicotine reward. Proc Natl Acad Sci USA. 2008;105:19480-5.

26. LeSage MG, Perry JL, Kotz CM, Shelley D, Corrigall WA. Nicotine selfadministration in the rat: effects of hypocretin antagonists and changes in hypocretin mRNA. Psychopharmacology (Berlin). 2010;209:203-12.

27. Plaza-Zabala A, Flores Á, Martín-García E, Saravia R, Maldonado R, Berrendero F. A role for hypocretin/orexin receptor-1 in cue-induced reinstatement of nicotineseeking behavior. Neuropsychopharmacology. 2013;38:1724-36.

28. Plaza-Zabala A, Martín-García E, Lecea L, de, Maldonado R, Berrendero F. Hypocretins regulate the anxiogenic-like effects of nicotine and induce reinstatement of nicotine-seeking behavior. J Neurosci J Soc Neurosci. 2010;30:2300-10.

29. Brown RM, Khoo SY-S, Lawrence AJ. Central orexin (hypocretin) 2 receptor antagonism reduces ethanol self-administration, but not cue-conditioned ethanol-seeking, in ethanol-preferring rats. Int J Neuropsychopharmacol. 2013;16:2067-79.

30. Dhaher R, Hauser SR, Getachew B, Bell RL, McBride WJ, McKinzie DL, et al. The orexin-1 receptor antagonist SB-334867 reduces alcohol relapse drinking, but not alcohol-seeking, in alcohol-preferring (P) rats. J Addict Med. 2010:4:153-9.

31. Anderson RI, Becker HC, Adams BL, Jesudason CD, Rorick-Kehn LM. Orexin-1 and orexin-2 receptor antagonists reduce ethanol self-administration in high-drinking rodent models. Front Neurosci. 2014;8:33.

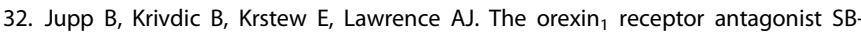
334867 dissociates the motivational properties of alcohol and sucrose in rats. Brain Res. 2011;1391:54-9.

33. Lopez MF, Moorman DE, Aston-Jones G, Becker HC (2016). The highly selective orexin/hypocretin 1 receptor antagonist GSK1059865 potently reduces ethanol drinking in ethanol dependent mice. Brain Res https://doi.org/10.1016/j. brainres.2016.01.049.

34. Martin-Fardon R, Weiss F. N-(2-methyl-6-benzoxazolyl)-N'-1,5-naphthyridin-4-yl urea (SB334867), a hypocretin receptor-1 antagonist, preferentially prevents ethanol seeking: comparison with natural reward seeking. Addict Biol. 2014b;19:233-6.

35. Olney JJ, Navarro M, Thiele TE. Binge-like consumption of ethanol and other salient reinforcers is blocked by orexin-1 receptor inhibition and leads to a reduction of hypothalamic orexin immunoreactivity. Alcohol Clin Exp Res. 2015;39:21-29.

36. Schmeichel BE, Barbier E, Misra KK, Contet C, Schlosburg JE, Grigoriadis D, et al. Hypocretin receptor 2 antagonism dose-dependently reduces escalated heroin self-administration in rats. Neuropsychopharmacology. 2015;40:1123-9.

37. Smith RJ, Aston-Jones G. Orexin/hypocretin 1 receptor antagonist reduces heroin self-administration and cue-induced heroin seeking. Eur J Neurosci. 2012;35:798-804.

38. Cason AM, Aston-Jones G. Attenuation of saccharin-seeking in rats by orexin/ hypocretin receptor 1 antagonist. Psychopharmacology (Berlin). 2013a;228:499-507.

39. Cason AM, Aston-Jones G. Role of orexin/hypocretin in conditioned sucrose seeking in rats. Psychopharmacology (Berlin). 2013b;226:155-65.

40. Mahler SV, Moorman DE, Smith RJ, James MH, Aston-Jones G. Motivational activation: a unifying hypothesis of orexin/hypocretin function. Nat Neurosci. 2014;17:1298-303.

41. Ahmed SH, Kenny PJ, Koob GF, Markou A. Neurobiological evidence for hedonic allostasis associated with escalating cocaine use. Nat Neurosci. 2002;5:625-6.

42. Ahmed SH, Koob GF. Transition from moderate to excessive drug intake: change in hedonic set point. Science. 1998;282:298-300.

43. Jonkman S, Pelloux $Y$, Everitt BJ. Drug intake is sufficient, but conditioning is not necessary for the emergence of compulsive cocaine seeking after extended selfadministration. Neuropsychopharmacology. 2012;37:1612-9.

44. Mantsch JR, Baker DA, Francis DM, Katz ES, Hoks MA, Serge JP. Stressor- and corticotropin releasing factor-induced reinstatement and active stress-related behavioral responses are augmented following long-access cocaine selfadministration by rats. Psychopharmacology (Berlin). 2008;195:591-603.

45. Mantsch JR, Yuferov V, Mathieu-Kia A-M, Ho A, Kreek MJ. Effects of extended access to high versus low cocaine doses on self-administration, cocaine-induced reinstatement and brain mRNA levels in rats. Psychopharmacology (Berlin). 2004;175:26-36.

46. Aujla H, Martin-Fardon R, Weiss F. Rats with extended access to cocaine exhibit increased stress reactivity and sensitivity to the anxiolytic-like effects of the mGluR 2/3 agonist LY379268 during abstinence. Neuropsychopharmacology. 2008;33:1818-26.

47. Orio L, Edwards S, George O, Parsons LH, Koob GF. A role for the endocannabinoid system in the increased motivation for cocaine in extended-access conditions. J Neurosci J Soc Neurosci. 2009;29:4846-57.

48. Pelloux Y, Everitt BJ, Dickinson A. Compulsive drug seeking by rats under punishment: effects of drug taking history. Psychopharmacology (Berlin). 2007;194:127-37.

49. Vanderschuren LJMJ, Everitt BJ. Drug seeking becomes compulsive after prolonged cocaine self-administration. Science. 2004;305:1017-9.

50. Wee S, Mandyam CD, Lekic DM, Koob GF. Alpha 1-noradrenergic system role in increased motivation for cocaine intake in rats with prolonged access. Eur Neuropsychopharmacol. 2008;18:303-11.

51. Darcq E, Koebel P, Del Boca C, Pannetier S, Kirstetter A-S, Garnier J-M, et al RSK2 signaling in brain habenula contributes to place aversion learning. Learn Mem. 2011;18:574-8.

52. Paxinos G, Watson C (Academic Press: 2013). The Rat Brain in Stereotaxic Coordinates. Available at http://store.elsevier.com/The-Rat-Brain-in-StereotaxicCoordinates/George-Paxinos/isbn-9780123919496/ 
53. Wee S, Vendruscolo LF, Misra KK, Schlosburg JE, Koob GF. A combination of buprenorphine and naltrexone blocks compulsive cocaine intake in rodents without producing dependence. Sci Transl Med. 2012;4:146ra110.

54. Zorrilla EP, Wee S, Zhao Y, Specio S, Boutrel B, Koob GF, et al. Extended access cocaine self-administration differentially activates dorsal raphe and amygdala corticotropin-releasing factor systems in rats. Addict Biol. 2012;17:300-8.

55. Vendruscolo LF, Pamplona FA, Takahashi RN. Strain and sex differences in the expression of nociceptive behavior and stress-induced analgesia in rats. Brain Res. 2004;1030:277-83.

56. Elias CF, Lee CE, Kelly JF, Ahima RS, Kuhar M, Saper CB, et al. Characterization of CART neurons in the rat and human hypothalamus. J Comp Neurol. 2001;432:1-19.

57. Herman MA, Sidhu H, Stouffer DG, Kreifeldt M, Le D, Cates-Gatto C, et al. GIRK3 gates activation of the mesolimbic dopaminergic pathway by ethanol. Proc Natl Acad Sci USA. 2015;112:7091-6.

58. Chou TC, Lee CE, Lu J, Elmquist JK, Hara J, Willie JT, et al. Orexin (Hypocretin) neurons contain dynorphin. J Neurosci. 2001;21:RC168.

59. Broberger C, De Lecea L, Sutcliffe JG, Hökfelt T. Hypocretin/orexin- and melaninconcentrating hormone-expressing cells form distinct populations in the rodent lateral hypothalamus: relationship to the neuropeptide $\mathrm{Y}$ and agouti gene-related protein systems. J Comp Neurol. 1998;402:460-74.

60. Elias CF, Saper CB, Maratos-Flier E, Tritos NA, Lee C, Kelly J, et al. Chemically defined projections linking the mediobasal hypothalamus and the lateral hypothalamic area. J Comp Neurol. 1998;402:442-59.

61. Borgland SL, Chang S-J, Bowers MS, Thompson JL, Vittoz N, Floresco SB, et al. Orexin A/hypocretin-1 selectively promotes motivation for positive reinforcers. J Neurosci. 2009;29:11215-25.

62. España RA, Melchior JR, Roberts DCS, Jones SR. Hypocretin 1/orexin A in the ventral tegmental area enhances dopamine responses to cocaine and promotes cocaine self-administration. Psychopharmacology (Berlin). 2011;214:415-26.

63. Koob GF, Buck CL, Cohen A, Edwards S, Park PE, Schlosburg JE, et al. Addiction as a stress surfeit disorder. Neuropharmacology. 2014;76 Pt B:370-82.

64. Hata $T$, Chen J, Ebihara K, Date $Y$, Ishida $Y$, Nakahara D. Intra-ventral tegmental area or intracerebroventricular orexin-A increases the intra-cranial self-stimulation threshold via activation of the corticotropin-releasing factor system in rats. Eur J Neurosci. 2011;34:816-26.

65. Harris GC, Wimmer M, ston-Jones G. A role for lateral hypothalamic orexin neurons in reward seeking. Nature. 2005;437:556-9.

66. Martin-Fardon R, Zorrilla EP, Ciccocioppo R, Weiss F. Role of innate and druginduced dysregulation of brain stress and arousal systems in addiction: Focus on corticotropin-releasing factor, nociceptin/orphanin $F Q$, and orexin/hypocretin. Brain Res. 2010;1314:145-61.

67. Matzeu A, Kerr TM, Weiss F, Martin-Fardon R. Orexin-A/hypocretin-1 mediates cocaine-seeking behavior in the posterior paraventricular nucleus of the thalamus via orexin/hypocretin receptor-2. J Pharmacol Exp Ther. 2016;359:273-9.

68. Johnson PL, Molosh A, Fitz SD, Truitt WA, Shekhar A. Orexin, stress, and anxiety/ panic states. Prog Brain Res. 2012;198:133-61.

69. Suzuki M, Beuckmann CT, Shikata K, Ogura H, Sawai T. Orexin-A (hypocretin-1) is possibly involved in generation of anxiety-like behavior. Brain Res. 2005;1044:116-21.

70. Hara J, Beuckmann CT, Nambu T, Willie JT, Chemelli RM, Sinton CM, et al. Genetic ablation of orexin neurons in mice results in narcolepsy, hypophagia, and obesity. Neuron. 2001:30:345-54.

71. Haynes AC, Jackson B, Chapman H, Tadayyon M, Johns A, Porter RA, et al. A selective orexin-1 receptor antagonist reduces food consumption in male and female rats. Regul Pept. 2000;96:45-51.

72. Yamada H, Okumura T, Motomura W, Kobayashi $Y$, Kohgo $Y$. Inhibition of food intake by central injection of anti-orexin antibody in fasted rats. Biochem Biophys Res Commun. 2000;267:527-31.

73. España RA, Plahn S, Berridge CW. Circadian-dependent and circadianindependent behavioral actions of hypocretin/orexin. Brain Res. 2002;943:224-36.

74. McGregor R, Wu M-F, Barber G, Ramanathan L, Siegel JM. Highly specific role of hypocretin (orexin) neurons: differential activation as a function of diurnal phase, operant reinforcement versus operant avoidance and light level. J Neurosci. 2011;31:15455-67.

75. Zheng H, Berthoud H-R. Eating for pleasure or calories. Curr Opin Pharmacol. 2007;7:607-12.

76. Choi DL, Davis JF, Fitzgerald ME, Benoit SC. The role of orexin-A in food motivation, reward-based feeding behavior and food-induced neuronal activation in rats. Neuroscience. 2010;167:11-20.
77. Thorpe AJ, Cleary JP, Levine AS, Kotz CM. Centrally administered orexin A increases motivation for sweet pellets in rats. Psychopharmacology (Berlin). 2005; $182: 75-83$.

78. de Lecea L, Sutcliffe JG, Fabre V. Hypocretins/orexins as integrators of physiological information: lessons from mutant animals. Neuropeptides. 2002;36:85-95.

79. Chen L, Thakkar MM, Winston S, Bolortuya Y, Basheer R, McCarley RW. REM sleep changes in rats induced by siRNA-mediated orexin knockdown. Eur J Neurosci. 2006;24:2039-48.

80. Kim T-K, Kim J-E, Park J-Y, Lee J-E, Choi J, Kim H, et al. Antidepressant effects of exercise are produced via suppression of hypocretin/orexin and melaninconcentrating hormone in the basolateral amygdala. Neurobiol Dis. 2015;79:59-69.

81. Prasad AA, McNally GP. Effects of vivo morpholino knockdown of lateral hypothalamus orexin/hypocretin on renewal of alcohol seeking. PLoS ONE. 2014;9: e110385.

82. Reissner KJ, Sartor GC, Vazey EM, Dunn TE, Aston-Jones G, Kalivas PW. Use of vivo-morpholinos for control of protein expression in the adult rat brain. J Neurosci Methods. 2012;203:354-60.

83. Chen L, McKenna JT, Bolortuya Y, Brown RE, McCarley RW. Knockdown of orexin type 2 receptor in the lateral pontomesencephalic tegmentum of rats increases REM sleep. Eur J Neurosci. 2013:37:957-63.

84. Chen L, McKenna JT, Bolortuya Y, Winston S, Thakkar MM, Basheer R, et al. Knockdown of orexin type I receptor in rat locus coeruleus increases REM sleep during the dark period. Eur J Neurosci. 2010;32:1528.

85. Choi DL, Davis JF, Magrisso IJ, Fitzgerald ME, Lipton JW, Benoit SC. Orexin signaling in the paraventricular thalamic nucleus modulates mesolimbic dopamine and hedonic feeding in the rat. Neuroscience. 2012;210:243-8.

86. Arendt DH, Hassell J, Li H, Achua JK, Guarnieri DJ, Dileone RJ, et al. Anxiolytic function of the orexin 2/hypocretin $A$ receptor in the basolateral amygdala. Psychoneuroendocrinology. 2014;40:17-26.

87. Sharf R, Sarhan M, Brayton CE, Guarnieri DJ, Taylor JR, DiLeone RJ. Orexin signaling via the orexin 1 receptor mediates operant responding for food reinforcement. Biol Psychiatry. 2010;67:753-60.

88. Li Y, van den Pol AN. Differential target-dependent actions of coexpressed inhibitory dynorphin and excitatory hypocretin/orexin neuropeptides. J Neurosci. 2006:26:13037-47.

89. Baimel C, Lau BK, Qiao M, Borgland SL. Projection-target-defined effects of orexin and dynorphin on VTA dopamine neurons. Cell Rep. 2017;18:1346-55.

90. Todtenkopf MS, Marcus JF, Portoghese PS, Carlezon WA. Effects of kappa-opioid receptor ligands on intracranial self-stimulation in rats. Psychopharmacology (Berlin). 2004;172:463-70.

91. Matzeu A, Kallupi M, George O, Schweitzer P, Martin-Fardon R (2017). Dynorphin counteracts orexin in the paraventricular nucleus of the thalamus: cellular and behavioral evidence. Neuropsychopharmacology. 2018;43:1010-1020. Epub ahead of print

92. Gao XB, van den Pol AN. Melanin concentrating hormone depresses synaptic activity of glutamate and GABA neurons from rat lateral hypothalamus. J Physiol. 2001;533:237-52.

93. Gao X-B, van den Pol AN. Melanin-concentrating hormone depresses L-, N-, and $\mathrm{P} / \mathrm{Q}$-type voltage-dependent calcium channels in rat lateral hypothalamic neurons. J Physiol. 2002;542:273-86.

94. van den Pol AN, Acuna-Goycolea C, Clark KR, Ghosh PK. Physiological properties of hypothalamic $\mathrm{MCH}$ neurons identified with selective expression of reporter gene after recombinant virus infection. Neuron. 2004;42:635-52.

95. Rao Y, Lu M, Ge F, Marsh DJ, Qian S, Wang AH, et al. Regulation of synaptic efficacy in hypocretin/orexin-containing neurons by melanin concentrating hormone in the lateral hypothalamus. J Neurosci. 2008;28:9101-10.

96. Barson JR, Morganstern I, Leibowitz SF. Complementary roles of orexin and melanin-concentrating hormone in feeding behavior. Int J Endocrinol. 2013;2013:983964.

97. Apergis-Schoute J, lordanidou $\mathrm{P}$, Faure $\mathrm{C}$, Jego $\mathrm{S}$, Schöne $\mathrm{C}$, Aitta-Aho $\mathrm{T}$, et al. Optogenetic evidence for inhibitory signaling from orexin to $\mathrm{MCH}$ neurons via local microcircuits. J Neurosci. 2015;35:5435-41.

98. Chung S, Hopf FW, Nagasaki H, Li C-Y, Belluzzi JD, Bonci A, et al. The melaninconcentrating hormone system modulates cocaine reward. Proc Natl Acad Sci USA. 2009;106:6772-7.

99. Cippitelli A, Karlsson C, Shaw JL, Thorsell A, Gehlert DR, Heilig M. Suppression of alcohol self-administration and reinstatement of alcohol seeking by melaninconcentrating hormone receptor $1(\mathrm{MCH} 1-\mathrm{R})$ antagonism in Wistar rats. Psychopharmacology (Berlin). 2010;211:367-75. 